Article

\title{
Stable Hydrogen and Oxygen Isotopes for Groundwater Sources of Penghu Islands, Taiwan
}

\author{
Hsin-Fu Yeh ${ }^{1, *(1)}$ and Jhe-Wei Lee ${ }^{2}$ \\ 1 Department of Resources Engineering, National Cheng Kung University, Tainan 701, Taiwan \\ 2 Department of Hydraulic and Ocean Engineering, Cheng Kung University, Tainan 701, Taiwan; \\ jheweilee@gmail.com \\ * Correspondence: hfyeh22@gmail.com; Tel.: +886-6-275-7575
}

Received: 26 October 2017; Accepted: 26 February 2018; Published: 1 March 2018

\begin{abstract}
This study used stable hydrogen and oxygen isotopes as natural tracers to investigate their isotopic composition in precipitation, and in shallow and deep groundwater in the Penghu Islands in the Taiwan Strait. We aimed to understand the differences and relationships in isotope compositions within various water bodies and to evaluate the source of groundwater recharge. The hydrogen and oxygen isotopic compositions of sampled groundwater are mainly distributed along the meteoric water line in the Penghu Islands, the variations in the distribution range being minor (the $\delta \mathrm{D}$ values are distributed from $-48.2 \%$ to $-37.7 \%$, with a mean value of $-43.14 \pm 2.4 \%$; the $\delta^{18} \mathrm{O}$ values are distributed from $-6.96 \%$ o to $-5.46 \%$, with a mean value of $-6.34 \pm 0.34 \%$ ). The data suggest that the groundwater is sourced mainly from local precipitation. In addition, a comparison of the hydrogen and oxygen isotopic compositions of groundwater and precipitation in Taiwan shows that the $\delta$ values for groundwater are distributed between those for precipitation during the northeast monsoon and the southwest monsoon seasons. However, some of the $\delta$ values trends towards the isotopic composition of the precipitation during the southwest monsoon season. Thus, the source of groundwater may have a closer association with precipitation during this time.
\end{abstract}

Keywords: hydrogen and oxygen isotopes; groundwater sources; Penghu Islands

\section{Introduction}

Previous studies have found that hydrogen and oxygen isotopes are not affected by the environment and degradation of water quality [1]. In addition, the generation and composition of these isotopes are controlled by different stages in the water cycle, and are associated with the movement of water bodies and hydrological processes, with low temporal variation. Thus, these stable isotopes can be used to investigate the behavior of water body movement in the stratum and the mutual relationships between various water bodies. The stable isotopes of hydrogen and oxygen were generally used to evaluate hydrological environments [2]. These isotopes have a wide range of applications, and are used in large-scale studies on the natural environment, where concentrations of the isotope components are variable. Differences in physical or chemical properties of the environment will result in isotope fractionation, which is preserved in the water cycle. Thus, changes in the natural hydrological environment are reflected by changes in the isotope ratios of hydrogen and oxygen, as observed in atmospheric precipitation models [3], in mutual interactions between groundwater and surface water [4], recharge processes and flow mechanisms of groundwater [5], and groundwater salinization mechanisms [6]. In small-scale studies, these isotopes are mainly used in methods similar to tracer calibration, to examine the movement of water in soil, and the source of moisture in soil absorbed by plants [7]. Isotopic studies can also be used to monitor groundwater flow in unsaturated porous layers [8] and to understand preferential flow pathways [9]. 
Meteoric water in different regions has different compositions of stable hydrogen and oxygen isotopes, due to isotope fractionation. When meteoric water seeps into the ground to form groundwater, its isotopic variation is recorded in the groundwater. Hence, differences in isotope compositions can be used as a basis for the detection of groundwater sources [10-13]. During the process of seawater evaporation to inland precipitation, continuous isotope fractionation causes changes in hydrogen and oxygen isotope compositions in meteoric water. As this process is based on isotopic fractionation during evaporation and condensation, there is a specific relationship between hydrogen and oxygen isotopic distributions in atmospheric precipitation. This relationship was first proposed by Craig [14], who analyzed $\mathrm{H}$ and $\mathrm{O}$ isotopic compositions in rain, snow, and river water samples from around the world and used linear regression to obtain the Global Meteoric Water Line $\left(\delta \mathrm{D}=8 \delta^{18} \mathrm{O}+10\right)$. The meteoric water line shows that the ratio of the two isotopes, $\delta \mathrm{D}$ and $\delta^{18} \mathrm{O}$, is about $8: 1$, with intercept value is around $10 \%$. The meteoric water line is an important reference line and tool in isotope hydrology research. Under room temperature conditions, stable hydrogen and oxygen isotopes in groundwater tend to preserve the same $\delta$ value as that in the initial meteoric water. Thus, the source and evolution process of groundwater in a specific location can be determined based on the groundwater's relationship with hydrogen and oxygen isotopes in meteoric water [11,15]. As hydrogen and oxygen isotopic composition of groundwater records weather conditions (e.g., temperature and humidity) at a given time, this tool can be used to investigate the causes of isotopic variations and thus distinguish the sources and partition of groundwater, allowing past weather conditions to be examined.

\section{Study Area}

The Penghu Islands have larger evaporation than precipitation and significant variation in precipitation during the wet and dry periods [16]. Since it has been difficult to store water in lake reservoirs, groundwater plays an important role in the water supply over time. However, due to excessive exploitation of groundwater resources, some areas show signs of seawater infiltration, which has caused a gradual increase in salinity of aquifers. Water shortages in the Penghu Islands are becoming increasingly significant, and thus groundwater usage is an important topic [17]. Obtaining better information on the sources of groundwater recharge and the effects of climate and monsoons on water resources would significantly aid in water resource management.

The Penghu Islands were selected as the main study site (Figure 1). The areas studied were Magong City, Huxi Township, Xiyu Township, and Baisha Township. The total study area is about $104 \mathrm{~km}^{2}$, which is about $80 \%$ of the area of the Penghu Islands. In the study area, the terrain is high in the South and low in the North, with no natural rivers and only artificial drainage canals. The average elevation is $30 \mathrm{~m}$, with the highest elevation being $74 \mathrm{~m}$. Due to the flat terrain of the Penghu Islands, during winter, there are no uplifting of air masses to form rain. During summer, the main source of precipitation is from typhoons. However, typhoons frequently arrive from the east of Taiwan and cross the Central Mountain Range, where most of the water vapor is intercepted. Therefore, precipitation in the Penghu Islands is far lower than that for Taiwan Island. The annual average rainfall is only $1000 \mathrm{~mm}$, which is mainly concentrated between May and September. The average evaporation in the Penghu Islands is $1450 \mathrm{~mm}$, resulting in a lack of usable surface water supply [18]. Figure 2 shows the monthly average rainfall and evaporation.

While the surface water supply in Penghu Islands is insufficient, the groundwater is more stable than surface water. Therefore, groundwater is the major source of water of this region. The subsurface hydrogeology of the Penghu Islands has an 80 and $40 \mathrm{~m}$ thickness of the shallow and deep aquifers, respectively, being interlaid with a clay layer $20-40 \mathrm{~m}$ thick. Wells in Penghu Islands were divided into shallow and deep wells. A total of 1825 shallow wells were recorded, which were mainly used for domestic purposes. The annual total pumping capacity was estimated to be 2.11 million $\mathrm{m}^{3}$. Deep wells mainly belonged to water companies, and 126 of them were recorded. The annual pumping capacity of the deep wells was estimated at 0.98 million $\mathrm{m}^{3}$ [19]. The islands have a flat terrain (i.e., no mountains). The natural surface vegetation consists of short grasses and shrubs, and there are no flow stoppage 
conditions, resulting in almost no rivers. Only a few reservoirs and ponds accumulate rainwater. Therefore, the source of groundwater in the Penghu Islands is worth investigating.

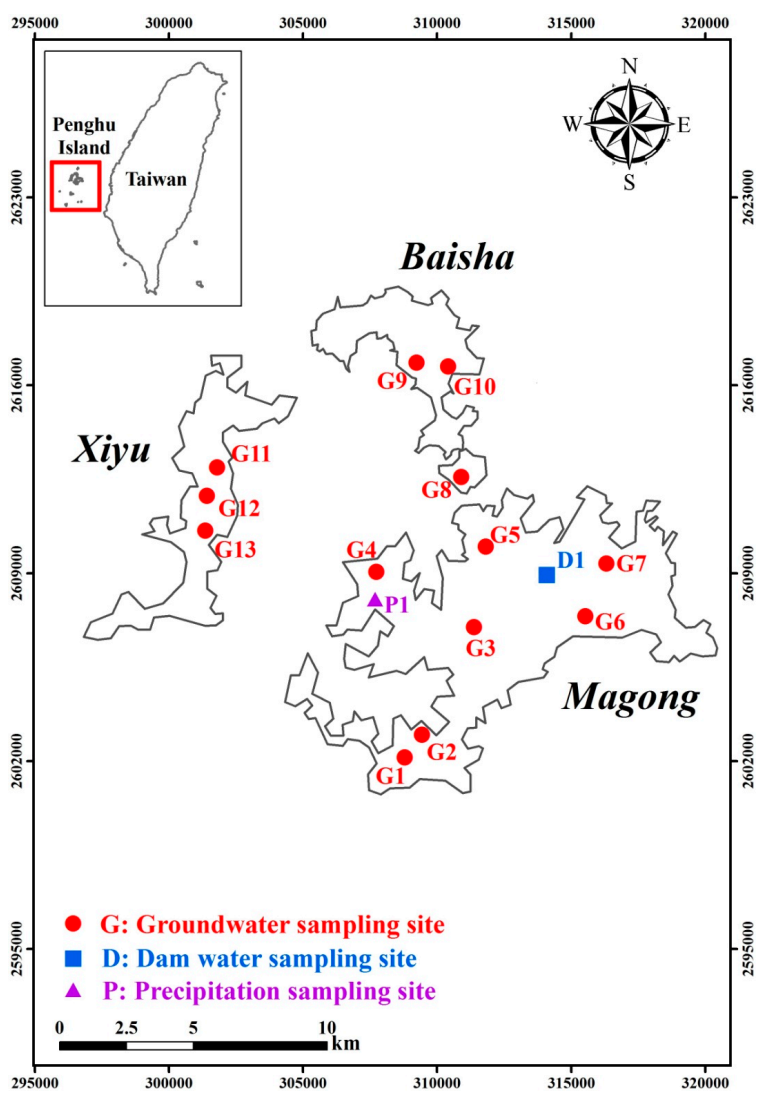

Figure 1. Locations of sampling sites in the study region.

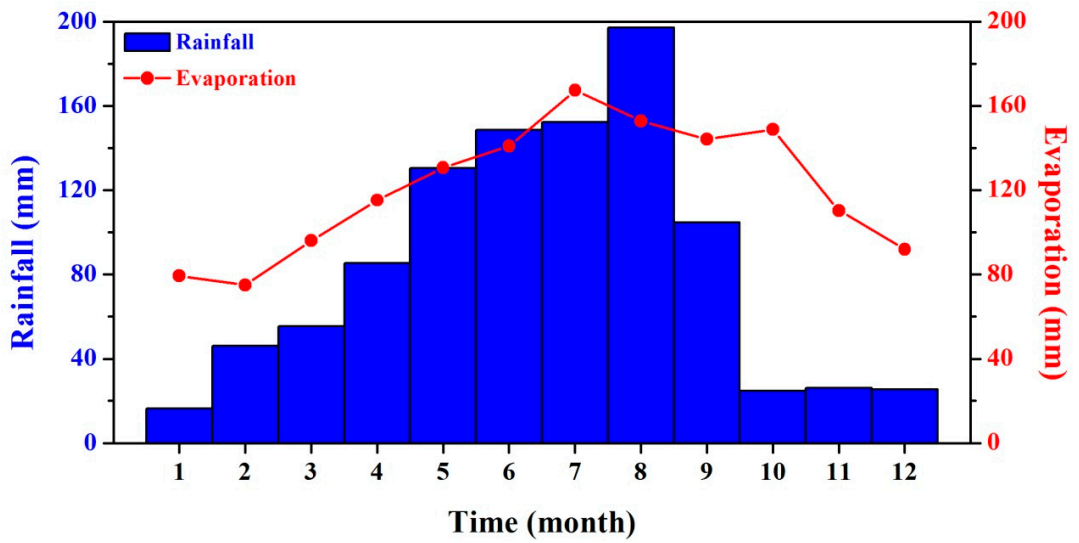

Figure 2. Monthly average of rainfall and evaporation in the Penghu Islands for the period 1981-2015.

\section{Sampling and Analytical Techniques}

We sampled rainwater, reservoir water, and groundwater from the Penghu Islands and analyzed their stable hydrogen and oxygen isotopic compositions. Duplicate samples were collected at every sampling point, each sample containing $100 \mathrm{~mL}$ of water. Figure 1 shows the sampling locations in the Penghu islands. Isotopic ratio measurements were carried out at the Research Center for Environmental Changes (RCEC) of the Academia Sinica, Taiwan. $\delta^{18} \mathrm{O}$ values were determined using the $\mathrm{CO}_{2}-\mathrm{H}_{2} \mathrm{O}$ equilibration method [20]. In the pretreatment system, standard $\mathrm{CO}_{2}$ with known 
$\delta^{18} \mathrm{O}$ values was allowed to react with the water samples at $30{ }^{\circ} \mathrm{C}$ for $2 \mathrm{~h}$. After equilibrium was achieved, freezing was used for water removal and purification, and $\mathrm{CO}_{2}$ was collected in a glass tube. Thereafter, isotope ratio mass spectrometry (IRMS) was used to quantify the oxygen isotopic compositions of the water samples that had achieved isotopic equilibrium with oxygen in the $\mathrm{CO}_{2}$ [21]. Extraction of hydrogen was carried out using zinc granules to produce hydrogen gas [22]. In this method, $200 \mathrm{~mL}$ of zinc granules were weighed and a capillary tube was used to remove $4 \mu \mathrm{L}$ of the water sample, and both were sealed in a $1 / 4^{\prime \prime}(6.35 \mathrm{~mm})$ vacuum Pyrex specimen. The sealed specimen tube was placed in a $500{ }^{\circ} \mathrm{C}$ oven for $30 \mathrm{~min}$ to allow the water sample to completely react with the zinc, producing hydrogen gas through reduction. The specimen tube was then moved to the IRMS instrument to quantify the hydrogen isotopic composition [23]. $\delta \mathrm{D}$ and $\delta^{18} \mathrm{O}$ were used to express the hydrogen and oxygen isotopic composition of the water sample relative to the standard mean ocean water (SMOW), given as

$$
\delta=\left(\frac{R_{\text {Sample }}}{R_{\text {SMOW }}}-1\right) \times 1000,
$$

with units of parts per mil (\%o). In the above equation, $\mathrm{R}$ is either ${ }^{2} \mathrm{H} /{ }^{1} \mathrm{H}$ or ${ }^{18} \mathrm{O} /{ }^{16} \mathrm{O}$. The RCEC uses International Atomic Energy Agency (IAES) standard water samples, V-SMOW (Vienna Standard Mean Ocean Water, $\delta \mathrm{D}=0 \%$ and $\delta^{18} \mathrm{O}=0 \%$ ) and SLAP (Standard Light Antarctic Precipitation, $\delta \mathrm{D}=-428 \%$ and $\delta^{18} \mathrm{O}=-55 \%$ ) as reference specimens for calibration during determination of hydrogen and oxygen isotopic compositions in water samples. In this project, the analytical standard deviation of oxygen was $0.1 \%$, and that of hydrogen was $1.5 \%$.

\section{Results}

A total of 38 rainwater isotope data from past investigations (e.g., Wang et al. [24], Wang et al. [25], Wang et al. [26], and the Central Geological Survey (CGS) by the Ministry of Economic Affairs [27]) and 5 isotope data from our own samples were used in this study. The results show that the $\delta \mathrm{D}$ values of rainwater were distributed between $-81.9 \%$ and $46.0 \%$, with an average value of $-18.9 \pm 27.4 \%$, and that the $\delta^{18} \mathrm{O}$ values were distributed between $-11.41 \%$ and $4.99 \%$, with an average value of $-3.7 \pm 3.4 \%$. The average value of the intercept was $10.8 \%$. Linear regression was used to evaluate the local meteoric water line (LMWL) for the Penghu Islands, which was found to be $\delta \mathrm{D}=8.02 \delta^{18} \mathrm{O}+10.84$ (Figure 3). The hydrogen and oxygen isotopic compositions in the Penghu Islands are consistent with the Global Meteoric Water Line (GMWL, $\left.\delta \mathrm{D}=8 \delta^{18} \mathrm{O}+10\right)$ (Craig [14]).

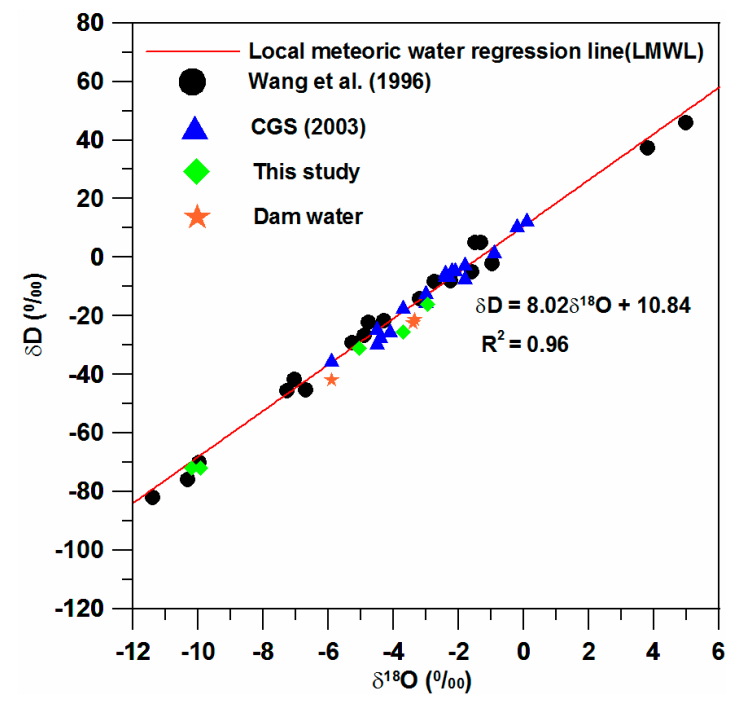

Figure 3. Plot of $\delta \mathrm{D}$ vs. $\delta 18 \mathrm{O}$ for precipitation samples. LMWL represents local meteoric water line for Penghu Islands. 
For the analysis of isotopic compositions of hydrogen and oxygen in groundwater, Wang et al. [26] pointed out that the $\delta^{18} \mathrm{O}$ of deep groundwater is distributed between $-6.46 \%$ and $-5.67 \%$, and $\delta \mathrm{D}$ is distributed between $-42.9 \%$ and $-34.1 \%$. It was further noted that the variation in deep groundwater is lower than that of rainwater (Figure 4). This is a characteristic signature of isotopic composition in groundwater. In addition, for shallow groundwater water, $\delta^{18} \mathrm{O}$ is distributed between $-7.09 \%$ and $-0.87 \%$, and $\delta \mathrm{D}$ is distributed between $-44.5 \%$ and $-0.1 \%$. Compared with the $\delta$ values of deep groundwater, the range of variation in shallow groundwater is larger. This implies that the effects of rainfall and evapotranspiration are more direct on shallow groundwater, and suggest the occurrence of possible seawater contamination. Overall, the $\delta$ values for both shallow and deep groundwater are distributed along the LMWL (Figure 4), showing that local rainfall is the main source of recharge for groundwater. The low variation in the distribution range indicates that the source of groundwater is simple. In addition, a comparison of $\delta \mathrm{D}$ and $\delta^{18} \mathrm{O}$ values of groundwater and precipitation in Taiwan show that the isotopic composition in groundwater is distributed between those of precipitation during the northeast and southwest monsoon seasons [28]. However, some of the $\delta$ values trend towards the isotopic composition of precipitation during the southwest monsoon season. The source of groundwater is thus more associated with precipitation during this season.

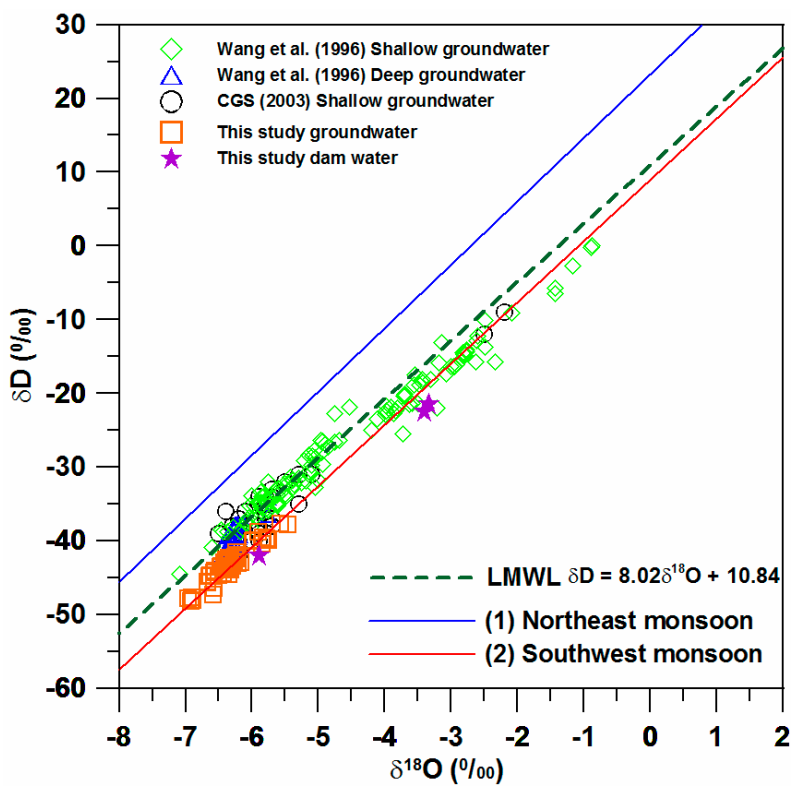

Figure 4. Plot of $\delta \mathrm{D}$ vs. $\delta 18 \mathrm{O}$ for shallow and deep groundwater samples. (1) Isotopic composition of precipitation during northeast monsoon season in Taiwan (meteoric water line: $\delta \mathrm{D}=8.6 \delta^{18} \mathrm{O}+23.3$ ); (2) Isotopic composition of precipitation during southwest monsoon season in Taiwan (meteoric water line: $\delta \mathrm{D}=8.3 \delta^{18} \mathrm{O}+9.0$ ) (Peng et al. [28]).

\section{Discussion}

According to Wang et al. [24], evaporation significantly affects the isotopic composition of surface water. Shallow groundwater is less affected, and deep groundwater is almost unaffected. The results of their study showed that there are no signs of seawater in deep groundwater, although some shallow groundwater has heavier isotopic compositions. However, it was not determined whether there is seawater contamination or whether this is due to strong evapotranspiration effects. However, whether this implies that the two types of groundwater have different supply mechanisms requires further identification.

In addition to the study by the CGS by the Ministry of Economic Affairs [27], we investigated 19 domestic wells (depth: $<10 \mathrm{~m}$ ) in shallow groundwater in the Penghu Islands. Sampling was carried out for each well in March and July. The results show that the $\mathrm{H}$ and $\mathrm{O}$ isotopic compositions of 
all samples were distributed along the meteoric water line (Figure 4), indicating that the meteoric source of shallow groundwaters in the Penghu Islands is from meteoric water. The $\delta \mathrm{D}$ values in March were distributed between $-43 \%$ and $-12 \%$, with an average of $-36 \pm 6 \%$; the $\delta^{18} \mathrm{O}$ values were distributed between $-6.5 \%$ and $-2.5 \%$, with an average of $-5.8 \pm 0.9 \%$. The average $d$ value was $11.0 \%$ in March. In July, the $\delta \mathrm{D}$ values were distributed between $-42 \%$ and $-9 \%$, with an average value of $-35 \pm 11 \%$; the $\delta^{18} \mathrm{O}$ values were distributed between $-6.5 \%$ and $-2.2 \%$, with an average value of $-5.6 \pm 1.4 \%$. The average $d$ value was $11.0 \%$ in July. A comparison of the hydrogen and oxygen isotopic compositions between March and July show that July had slightly higher average values with a higher standard deviation. This could be due to the relatively larger effects of rainwater on shallow groundwater during summer (July).

In this study, we collected 52 groundwater samples from the Penghu Islands. Groundwater $\delta \mathrm{D}$ values were distributed between $-48.2 \%$ and $-37.7 \%$, with an average value of $-43.14 \pm 2.4 \%$. The $\delta^{18} \mathrm{O}$ values were distributed between $-6.96 \%$ and $-5.46 \%$, with an average value of $-6.34 \pm 0.34 \%$. The groundwater samples collected in this study belongs to deep groundwater. The $\mathrm{H}$ and $\mathrm{O}$ isotopic composition results are consistent with the data from Wang et al. [26], which showed that the isotopic compositions in deep groundwater have a smaller distribution range (Figure 4). The $\delta \mathrm{D}$ and $\delta^{18} \mathrm{O}$ values plot along the LMWL of the Penghu Islands. The low variation in the distribution range indicates that the source of groundwater is simple. In addition, as there are no rivers in the Penghu Islands, we collected samples from reservoirs. Reservoir water samples were collected thrice; their mean $\delta$ values were $-28.7 \%$ and $-4.2 \%$ for hydrogen and oxygen respectively. These values were also distributed along the meteoric water line.

Results from previous studies and our isotope ratio data (from rainwater, shallow groundwater, deep groundwater, and reservoir water) were integrated for discussion. The distribution of hydrogen and oxygen isotopic compositions show that all water bodies are distributed along the meteoric water line. Regression of $\delta \mathrm{D}$ and $\delta^{18} \mathrm{O}$ in the Penghu islands and the LMWL was very consistent, as shown in Figure 4. Deep groundwater was distributed in areas with light isotopic compositions. Taking into account the average values, $\delta \mathrm{D}$ and $\delta^{18} \mathrm{O}$ values of rainwater were $-18.9 \%$ and $-3.7 \%$, respectively; those for shallow groundwater were $-28.8 \%$ and $-4.8 \%$, respectively; and for deep groundwater were $-41.8 \%$ and $-6.3 \%$, respectively. The $\delta$ values of shallow groundwater fall between those of rainwater and deep groundwater, and notably, they are closer to those of the latter. The isotopic compositions of shallow and deep groundwater were significantly lighter than those of modern rainwater, indicating that such groundwater could possibly originate from seepage of meteoric water in the past during colder climates. The heavier isotopic compositions of shallow groundwater compared to those of deep groundwater could be related to the effects of modern rainwater on shallow groundwater. Such effects are more pronounced during summer than in winter, as reported by the CGS [27], which found that the average $\delta \mathrm{D}$ and $\delta^{18} \mathrm{O}$ values in shallow groundwater during July were slightly heavier, but not very significantly. Overall, $\mathrm{H}$ and $\mathrm{O}$ isotopic signatures indicate that modern rainwater is not the main source of groundwater in the Penghu Islands, and that the source of shallow groundwater is related or similar to the source of deep groundwater. Therefore, the groundwater resources are limited, or there are other sources of recharge. Further studies that involve radioactive carbon dating or quantification of tritium isotopes (recharge by modern rainwater) should be carried out to confirm our results.

\section{Conclusions}

This study evaluates the distribution of $\delta \mathrm{D}$ and $\delta^{18} \mathrm{O}$ in the Penghu Islands. All water bodies are distributed along the meteoric water line. The slope and intercept of the LMWL was consistent with the equation of the Global Meteoric Water Line. A comparison of the isotope ratios in shallow groundwater and deep groundwater in the Penghu Islands demonstrate that the variation in the isotopic composition in shallow groundwater was greater, indicating that shallow water bodies are directly affected by rainfall and evapotranspiration. Overall, shallow and deep groundwater are distributed along the 
LMWL, showing that local rainfall is the main source of recharge for groundwater. The low variation in the distribution range indicates that the source of groundwater is simple. In addition, a comparison of the $\mathrm{H}$ and $\mathrm{O}$ isotopic compositions of groundwater and precipitation in Taiwan showed that the source of groundwater is largely associated with precipitation during the southwest monsoon season.

Acknowledgments: The authors would like to thank the Water Resources Agency of the Ministry of Economic Affairs of the Republic of China, Taiwan for financially supporting this research under grant MOEAWRA1050378. We would also like to thank Mao-Chang Liang of the Research Center for Environmental Changes at Academia Sinica for his help with water sample analysis. The comments from anonymous reviewers were greatly appreciated.

Author Contributions: Hsin-Fu Yeh conceived the subject of the article, literature review and contributed to the writing of the paper; Jhe-Wei Lee participated in data processing, elaborated the statistical analysis, and produced the figures.

Conflicts of Interest: The authors declare no conflict of interest.

\section{References}

1. Clark, I.D.; Fritz, P. Environmental Isotopes in Hydrology; Lewis Publishers: New York, NY, USA, 1997.

2. Kendall, C.; McDonnell, J.J. Isotope Tracers in Catchment Hydrology; Elsevier: Amsterdam, The Netherlands, 2012.

3. Gorski, G.; Strong, C.; Good, S.P.; Bares, R.; Ehleringer, J.R.; Bowen, G.J. Vapor hydrogen and oxygen isotopes reflect water of combustion in the urban atmosphere. Proc. Natl. Acad. Sci. 2015, 112, 3247-3252. [CrossRef] [PubMed]

4. Zhan, L.; Chen, J.; Zhang, S.; Li, L.; Huang, D.; Wang, T. Isotopic signatures of precipitation, surface water, and groundwater interactions, Poyang Lake Basin, China. Environ. Earth Sci. 2016, 75, 1307. [CrossRef]

5. Liu, J.; Chen, Z.; Zhang, Y.; Li, Z.; Zhang, L.; Liu, F. Stable isotope evidences on sources and mechanisms of groundwater recharge in Hohhot basin, China. Environ. Earth Sci. 2016, 75, 1-10. [CrossRef]

6. Carreira, P.M.; Marques, J.M.; Nunes, D. Source of groundwater salinity in coastline aquifers based on environmental isotopes (Portugal): Natural vs. human interference. A review and reinterpretation. Appl. Geochem. 2014, 41, 163-175. [CrossRef]

7. Wu, Y.; Du, T.; Li, F.; Li, S.; Ding, R.; Tong, L. Quantification of maize water uptake from different layers and root zones under alternate furrow irrigation using stable oxygen isotope. Agric. Water Manag. 2016, 168, 35-44. [CrossRef]

8. $\quad$ Rothfuss, Y.; Merz, S.; Hermes, N.; Weuthen, A.; Pohlmeier, A.; Vereecken, H.; Brüggemann, N. Long-term and high-frequency non-destructive monitoring of water stable isotope profiles in an evaporating soil column. Hydrol. Earth Syst. Sci. 2015, 19, 4067-4080. [CrossRef]

9. Ma, B.; Liang, X.; Liu, S.; Jin, M.; Nimmo, J.R.; Li, J. Evaluation of diffuse and preferential flow pathways of infiltrated precipitation and irrigation using oxygen and hydrogen isotopes. Hydrogeol. J. 2017, 25, 675-688. [CrossRef]

10. Yeh, H.F.; Lee, C.H.; Hsu, K.C. Oxygen and hydrogen isotopes for the characteristics of groundwater recharge: A case study from the Chih-Ben Creek basin, Taiwan. Environ. Earth Sci. 2011, 62, 393-402. [CrossRef]

11. Liu, Y.; Yamanaka, T. Tracing groundwater recharge sources in a mountain-plain transitional area using stable isotopes and hydrochemistry. J. Hydrol. 2012, 464-465, 116-126. [CrossRef]

12. Ding, Z.; Ma, J.; Zhao, W.; Jiang, Y.; Love, A. Profiles of geochemical and isotopic signatures from the Helan Mountains to the eastern Tengger Desert, northwestern China. J. Arid Environ. 2013, 90, 77-87. [CrossRef]

13. Peng, T.R.; Huang, C.C.; Zhan, W.J.; Wang, C.H. Assessing groundwater sources and their association with reservoir water using stable hydrogen and oxygen isotopes: A case study of the Taipei Basin, northern Taiwan. Environ. Earth Sci. 2016, 75, 1-13. [CrossRef]

14. Craig, H. Isotopic variations in meteoric waters. Science 1961, 133, 1702-1703. [CrossRef] [PubMed]

15. Yeh, H.F.; Lin, H.I.; Lee, C.H.; Hsu, K.C.; Wu, C.S. Identifying seasonal groundwater recharge using environmental stable isotopes. Water 2014, 6, 2849-2861. [CrossRef]

16. Jang, C.S.; Liu, C.W.; Chen, S.K.; Lin, W.S. Using a mass balance model to evaluate groundwater budget of seawater-intruded island aquifers. J. Am. Water Resour. Assoc. 2012, 48, 61-73. [CrossRef]

17. Water Resources Agency. Integrated Groundwater Conservation Strategy Planning for Penghu Region; Ministry of Economic Affairs of the Republic of China: Taipei, Taiwan, 2012. (In Chinese) 
18. Water Resources Agency. Hydrological Year Book of Taiwan; Ministry of Economic Affairs: Taipei, Taiwan, 2015. (In Chinese)

19. Water Resources Agency. A Quantitative Investigation on Sea Water Intrusions in the Penghu Area and Its Related Remediation Strategy; Ministry of Economic Affairs of the Republic of China: Taipei, Taiwan, 2016. (In Chinese)

20. Epstein, S.; Mayeda, T. Variation of ${ }^{18} \mathrm{O}$ content of waters from natural sources. Geochim. Cosmochim. Acta 1953, 4, 213-224. [CrossRef]

21. Berninkmeijer, C.A.M.; Kraft, P.; Mook, W.G. Oxygen isotope fractionation between $\mathrm{CO}_{2}$ and $\mathrm{H}_{2} \mathrm{O}$. Isotope Geosci. 1983, 1, 181-190. [CrossRef]

22. Coleman, M.L.; Shepherd, T.J.; Durham, J.J.; Rouse, J.E.; Moore, G.R. Reduction of water with zinc for hydrogen isotope analysis. Anal. Chem. 1982, 54, 993-995. [CrossRef]

23. Wang, C.H.; Yeh, H.W.; Tsai, P.S.; Wu, S.F. Hydrogen Stable Isotope Determination of Water Samples by Zinc Shot Reduction; Institute of Earth Sciences, Academia Sinica: Taipei, Taiwan, 1993.

24. Wang, C.H.; Chen, P.F.; Peng, T.R.; Yeh, C.C. A Preliminary Report on Stable Isotope Geochemistry in Groundwater of the Penghu Islands; Institute of Earth Sciences, Academia Sinica: Taipei, Taiwan, 1990.

25. Wang, C.H.; Peng, T.R.; Tsai, P.S.; Wu, S.F.; Shieh, Y.T.; Cherng, F.P. Stable isotopes compositions of groundwater from Penghu Islands and its implications. In Proceedings of the First Symposium on Groundwater Resources and Water Protection, Taipei, Taiwan, 29 April 1994.

26. Wang, C.H.; Lin, Y.L.; Chang, T.C.; Lee, L.A.; Lee, H.H.; Chuang, T.M.; Lin, K.; Lu, C.S. The Salinization of Groundwater in the Chih-Kan Subsurface Reservoir of Penghu Islands; Institute of Earth Sciences, Academia Sinica: Taipei, Taiwan, 1996.

27. Central Geological Survey (CGS). Study of Stable Hydrogen and Oxygen Isotopes for Groundwater in Penghu, Hsinchu-Miaoli and Chianan Areas; Ministry of Economic Affairs: Taipei, Taiwan, 2003. (In Chinese)

28. Peng, T.R.; Wang, C.H.; Huang, C.C.; Fei, L.Y.; Chen, C.T.A.; Hwong, J.L. Stable isotopic characteristic of Taiwan's precipitation: A case study of western Pacific monsoon region. Earth Planet. Sci. Lett. 2010, 289, 357-366. [CrossRef] 